\title{
LA PROBLEMATICIDAD DEL SUJETO FEMENINO EN THE RIGHTS Y THE WRONGS OF WOMAN DE MARY WOLLSTONECRAFT
}

ÁNGeles de la CONCHA

UNED

En 1929, en su obra Women and Writing ${ }^{1}$, Virginia Woolf escribía, como elogio, de Mary Wollstonecraft que sus ideas y sus convicciones, $\tan$ revolucionarias en su momento, no decían por entonces nada nuevo. Su originalidad de antaño se había disuelto y pasaba desapercibida en la rutina de lo conseguido. Y, aparentemente, la afirmación no deja de ser cierta. La lectura de sus dos Vindicaciones, tanto la de los derechos del hombre como la de los de la mujer muestran claramente que acuñaciones felices de conceptos tales como «la mujer no nace, se hace» de Simone de Beauvoir tienen una deuda explícita con la idea de «situación» desarrollada por Wollstonecraft que explicaba, casi dos siglos antes, el carácter cultural de rasgos femeninos considerados naturales por comparación con otros grupos sociales que los compartían.

Sin embargo, resulta de particular, y tristemente actual, relevancia hoy, cuando la mujer parece haber conseguido tantas cosas, la dialéctica sobre la identidad femenina fundamentada en la binariedad excluyente de los polos de sentimiento y razón según los sexos que subyace a lo largo de su obra. Cuan-

1 VIRGINIA Woolf, Women and Writing, Introduced by Michele Barrett, London; The Women's Press, 1979, p. 98. 
do la postmodernidad ha concluído con la rigidez de las categorías y los límites definitorios y se hace evidente el carácter cultural de concepciones históricamente esencialistas, se advierte el resurgir de estereotipos sexuales que actúan con enorme fuerza prescriptiva contribuyendo a reforzar conceptos de identidad que parecían superados. La cuestión no se limita sólo a problemas conceptuales ni teóricos, aunque cierto es que estos suelen preceder a acciones concretas que resultan en la práctica en retrocesos de derechos mínimos conseguidos tras pacientes forcejeos y todo tipo de negociaciones y renegociaciones. Que a finales del siglo XX todavía se utilice deliberada y masivamente, no como barbarie aislada, la violencia sexual sobre la mujer como arma intimidatoria en conflictos bélicos como el yugoslavo es triste índice de la consideración que se tiene sobre su ser fuera de núcleos privilegiados de población. $E$ incluso en estos, los logros elementales nunca están asegurados. Es significativo que todavía en 1972 hubiera de aprobarse por el Congreso en los Estados Unidos, el país supuestamente más avanzado en estos temas, una enmienda que garantizara la igualdad de derechos de la mujer. Lo que venía a reconocer, como las feministas habían denunciado una y otra vez, que el término hombre en su pretendido sentido de sujeto universal no era tan universal como se proclamaba, al evidenciarse que, al menos en el contexto «derechos del hombre», no incluía a la mujer. Más significativo aún es la polémica y la controversia que tal enmienda suscitó y las reacciones solapadas en su contra ${ }^{2}$. Pero veinte años más tarde, todavía en 1993 necesitamos otra declaración similar, esta vez a nivel mundial. Ahora es la ONU la que en la Conferencia Internacional sobre Derechos Humanos en Viena (junio 1993) se ve obligada a reconocer por primera vez en la historia que «los derechos humanos de las mujeres y niñas son inalienables y parte integral e indivisible de los derechos humanos" ${ }^{3}$. Y la conferencia, seguramente sensibilizada ante la amnesia histórica que debilita la fuerza de una declaración tras otra, acordaba el establecimiento de un cargo permanente para una relatora especial de la ONU sobre la violencia contra las mujeres. Está claro que la apreciación de Virginia Woolf era tan optimista como profético el pesimismo de Mary Wollstonecraft al comprobar el escaso éxito de la razón a pesar de la evidencia de sus argumentos.

La obra de Wollstonecraft tuvo la originalidad de constituir la primera exploración de los problemas sociales y morales en un momento histórico concreto, desde un punto de vista que consideraba la humanidad real, afron-

2 Vid. Susan FALUd, Backlash. The Undeclared War Against American Women, New York: Crown Publishers, 1991.

3 Vid. el diario El País, 26 de junio, 1993, p. 4. 
tando con clarividencia las dificultades especificas por razón de género. Por primera vez, una mujer tomaba la pluma para exponer sus propias opiniones sin recurrir a subterfugios de forma o de expresión. Sin subversiones solapadas del texto, y sin justificaciones y excusas vergonzantes, como el recurso de advocar la necesidad económica o la finalidad didáctica o moral de la obra, que de un modo u otro se encuentran persistentemente en la escritura de las mujeres de la época.

Y no es que en ella no concurrieran ambas premisas, la necesidad económica y la finalidad didáctica; pero animadas del poderoso incentivo que la revolución había prestado al pensamiento ilustrado, su punto de arranque, su trayectoria y su finalidad son muy otras. Bajo el estímulo de la necesidad empezó a practicar la independencia económica, que posteriormente sería uno de los principios de su enseñanza, y sufrió en su carne la experiencia de la falta de una educación que le permitiera conseguirla con dignidad. No puede extrañar, pues, el empeño y el ardor con que defiende el que la mujer se eduque como un ser autónomo en lugar de como satélite del hombre. Precisamente el hecho de haber vivido personalmente la mayoría de las constricciones y agravios comparativos que sufrían las mujeres, junto con lo espontáneo y apasionado de su temperamento y la lucidez de su juicio es lo que dota a su obra de un aliento que la hace perdurar, a pesar del proceso de solubilidad que Virginia Woolf señalaba.

$A$ Vindication of the Rights of Woman ${ }^{4}$ es una obra que interesa, y que se ha analizado, tanto desde el punto de vista literario como desde el filosófico, el de teoría crítica, o el sociológico porque es un texto en el que confluyen, se oponen y se modifican diversos discursos. Constituye, asimismo, un eslabón significativo de una obra orgánica, bien que inconclusa, tempranamente interrumpida por la muerte.

Este principio de organicidad que articula el conjunto de los escritos de Mary Wollstonecraft se advierte tanto en el proceso de su pensamiento que va evolucionando de obra en obra, como en la integración de teoría y praxis, y en la modificación gradual de aquélla por ésta. Del análisis de su correspondencia, las dos vindicaciones y sus obras de ficción, se desprende la naturaleza de sus preocupaciones morales y políticas, y la clarividencia de la dificultad de armonizar un temperamento emotivo y apasionado con la convicción de los Ilustrados de la total primacía de la razón. Si a ello unimos su desprecio por el prejuicio, su hostilidad al privilegio de la herencia y su fe en la capacidad hu-

4 Mary Wollstonecraft, A Vindication of the Rights of Woman; John Stuart MrLl, The Subjection of Women, London: Dent, 1982 (1929). Las sucesivas referencias a la obra aparecen en el texto con los números de las páginas entre paréntesis. 
mana de progreso, en el poder del libre albedrio - they alone are subject to blind authority who have no reliance on their own strength. They are free who will be free (111), exclama en la Vindication of the Rights of Woman- y a la vez la conciencia creciente de la impermeabilidad y la resistencia social al cambio, tendremos una idea aproximada de lo complejo de su personalidad y lo arduo de su tarea.

Mary Poovey en su obra The Proper Lady and the Woman Writer ${ }^{5}$ hace un detallado análisis de la obra de Mary Wollstonecraft en el que, si bien sus juicios puntuales son precisos y acertados, la tesis general que los enmarca es difícilmente aceptable. Poovey se esfuerza en mostrar la fisura nunca resuelta entre razón y sentimiento, traducida a su juicio en la incoherencia de su discurso, en el que la argumentación racional sería una y otra vez minada por un sentimentalismo burgués que le impediría la conclusión lógica y, en consecuencia, debilitaría el radicalismo del mensaje. Insistentemente resalta, a veces de manera forzada, esta supuesta incoherencia reforzándola con documentos extracontextuales, como cartas de la adolescencia o de circunstancias de su vida en las que expresa estados de ánimo emocionales lejos de la racionalidad defendida en las vindicaciones. Ahora bien, teniendo en cuenta la rigidez de las convenciones sociales de la época y los obstáculos y prohibiciones de todo tipo que cercaban la actividad de las mujeres y, a pesar de ello, la vida personal de Wollstonecraft marcada por rupturas y audacia extremas, no puede en absoluto extrañar que se debatiera en oscilaciones emocionales y sentimientos encontrados. Parece por ello a todas luces injusto tachar de fracaso su proyecto y achacar ese fracaso a una pretendida fractura irreconciliable entre la aspiración de Wollstonecraft a la autonomía intelectual y la independencia de espíritu con su conformación burguesa y sentimental ${ }^{6}$. Es necesario, además, un enfoque crítico en sus justos términos que analice las contradicciones, que evidentemente existen, como los pasos necesarios de un largo proceso, aún hoy no culminado, de exploración y definición de la identidad de la mujer en el marco de una organización social claramente opuesta a cualquier afirmación de autonomía femenina.

5 Mary Poovey, The Proper Lady and the Woman Writer. Ideology as style in the works of Mary Wollstonecraft, Mary Shelley, and Jane Austen, Chicago \& London: University of Chicago Press, 1984, cap. 2, «Man's Discourse, Woman's Heart: Mary Wollstonecraft's Two Vindications».

6 Janet Todd expresa sus dudas sobre la interpretación de Poovey en el capftulo «Readings of Mary Wollstonecraft» de su obra Feminist Literary History: A Defence, Oxford: Basil Blackwell, 1988, pp. 103, 104. 
Quizá sería bueno empezar por un comentario breve a una vindicación más desconocida, $A$ Vindication of the Rights of Men, publicada anónimamente en noviembre de 1790 , la primera y más inmediata respuesta a las Reflections on the Revolution in France de Edmund Burke, y que fue tan popular en su momento que se reeditó casi inmediatamente, en diciembre del mismo año, la segunda vez ya con el nombre de su autora. Con su obra Burke respondía a un discurso de Richard Price, pastor protestante y conocido radical inconformista, con ocasión de la conmemoración de la Revolución Inglesa de 1688, la conocida con el nombre de Gloriosa, y que se publicaría en 1789 con el nombre Discourse on the Love of Our Country. En él Price celebraba la promesa de la Revolución Francesa de libertad religiosa y civil. Burke, por contra, en su respuesta alertaba contra los peligros de la Revolución con un encendida defensa de los valores de la tradición y las costumbres.

Del fundamento de la argumentación contra Burke, lo que aquí nos interesa recoger es la crítica a la "obediencia dignificada» a las instituciones del estado y el principio de la «subordinación natural» de unas personas a otras que Burke preconizaba y de la que las mujeres eran paradigma. Wollstonecraft denuncia la falacia del argumento porque, tanto por experiencia personal y familiar como por la observación social que evidencia su análisis, sabía perfectamente que «la sumisión del corazón» sólo producía dependencia y sufrimiento. Desecha, pues, firmemente el paradigma femenino y lo sustituye por una descripción de la naturaleza y de la sociedad humanas fundamentada en la naturaleza de la actuación, el carácter y las virtudes masculinas.

Wollstonecraft, no obstante, no cae en la simplificación de percibir el problema exclusivamente en términos de género. Es perfectamente consciente de que no son las mujeres las únicas que sufren los males del despotismo. Observa y denuncia, por tanto, la importancia decisiva de la variable de la clase social en la configuración del carácter del individuo, afirmando que mientras sean la propiedad privada y el rango social los factores determinantes del valor y de la posición del individuo, la sumisión será la regla general. Particularmente vibrante es su denuncia de la consolación que se le brinda al pobre de que encontrará retribución en la «justicia eterna», el asimismo eterno argumento para aplacar al débil bajo el sofisma de la humildad de corazón y la sumisión a la voluntad celestial. Para Wollstonecraft la virtud sólo puede florecer entre iguales y la sumisión, junto con la condescendencia de la limosna -frente a la exigencia de la justicia- degrada tanto al que la sufre como al que la ejerce.

El análisis tiene la clarividencia de enfocar la situación femenina exactamente como situación, en contraste con el fuerte sentimiento esencialista que impregna la cultura y los usos sociales de la época. Para Wollstonecraft, al 
igual que los ricos heredan el privilegio - aunque fuera luego fuente de debilitamiento- por derecho natural de nacimiento, las mujeres adquieren el "privilegio» a través de la educación que convierte en «natural» su dependencia del hombre. A diferencia de los ricos, sin embargo, las mujeres no adquieren con él la seguridad en sí mismas ni el poder que les permita liberarse de una existencia atrofiada. La pasividad de las mujeres se refuerza a través de las mismas leyes políticas y económicas que legitiman la propiedad. Wollstonecraft divisa, así, las conexiones que existen entre la pugna de las mujeres y la de las clases sociales y de qué modo las categorías de valoración femenina que se le inculcan a la mujer emergen de las necesidades de los que gobiernan.

El problema radica en que desde su posición autorial, Wollstonecraft se sitúa claramente en otro campo del de las mujeres y no muestra excesiva simpatía ni comprensión ante esta sumisión que se les ha impuesto. Probablemente por el mismo concepto de situación que maneja, identifica su tratamiento de la opresión de la mujer con el de los otros grupos sociales asimismo en situación de dependencia. Imbuída del radicalismo revolucionario de los disidentes, además de atacar a los que ejercen la tiranía, o la defienden de hecho, como en el caso de Burke, flagela a los que se someten: las mujeres que se inclinan ante las virtudes masculinas, los ricos que ceden a la tentación de la indolencia, el clero que se arrastra ante los poderosos, los pobres que se someten a sus señores. Y en lugar de examinar la situación que provoca tal sometimiento, dejando de lado la experiencia femenina de incapacidad y frustración, se pronuncia por la convicción de que el individuo es capaz de conseguir lo que se propone.

Para Poovey, a quien sigo en su argumentación, lo que Wollstonecraft está haciendo, en realidad, es aliarse explícitamente con los valores individualistas y el ideal burgués - y también puritano- de la clase media al menospreciar la indefensión que concibe tan sólo como debilidad y fracaso personal. Pero, a mi juicio, es el ideal de la Ilustración de la fe ciega en la razón y en el poder de su proyecto emancipatorio, así como de su extensión universal, lo que confiere aliento al discurso. La mujer tiene que vencer su vulnerabilidad con la razón que ha de encauzar activamente los sentimientos. Precisamente la problematicidad que exhibe la obra de Mary Wollstoncraft pone de relieve, no hoy a posteriori desde nuestra conciencia postmoderna sino en su mismo momento histórico, el no cumplimiento del proyecto ilustrado del que la exclusión de la mujer de la categoría de sujeto universal, desde su misma génesis, es clara evidencia.

El tono y la voz narrativa no son producto de un sentimiento incontrolado, como se le achaca insistiendo de nuevo en sus contradicciones internas, si- 
no los propios de la arenga política en cuyo género literario y polémico se inscriben. Calculados para demoler el argumento del contrario, no vacilan en la desarticulación argumentativa mediante la acusación personal o la atribución de intenciones interesadas al adversario. La ironía y el sarcasmo alternan con el tono rotundo y directo tanto de afirmaciones universales incuestionables como de denuncias sociales flagrantes.

El subgénero elegido, el de la carta abierta, y la explícita alianza que la voz narrativa establece desde un principio con el sujeto universal masculino ${ }^{7}$, le permiten adoptar una posición de total igualdad con el destinatario y desligarse de cualquier conexión con el género femenino. $\mathrm{Y}$ aquí está el espinoso meollo de la cuestión: en la naturalidad misma de la exclusión, dada la exacta correspondencia del sujeto universal con el del género masculino. Las mujeres, no solo son designadas como «ellas», nunca «nosotras», sino incluso se las utiliza para reforzar un comentario despectivo en el que la alianza de género y clase en la personificación de la mujer de mundo, reduplica la intención ofensiva ${ }^{8}$. Por contra, actos positivos como «trabajar por incrementar la felicidad humana mediante la extirpación del error» (53) - lo que supone la intervención de la razón, atributo consensuadamente masculino- son definidos contra un paradigma universal masculino que al incluir en el término comparativo el concepto de la divinidad, excluye aún más radicalmente a la mujer. Tal empresa, escribe «is a masculine godlike affection» (53).

En 1792 Wollstonecraft publica $A$ Vindication of the Rights of Woman, lo que hace suponer que era consciente de que las mujeres no quedaban suficientemente explicitadas como sujetos de derecho dentro del término universal Men.

En ella insiste en que la condición de la mujer surge, en primer término, de su situación que no es de ningún modo natural sino adquirida. En segundo lugar, demuestra que las actitudes y expectativas que perpetúan la debilidad de la mujer están institucionalizadas a través de los textos que se erigen en autoridad. Desde su infancia se les ha instruido para que su concepto de sí mismas esté de acuerdo con el concepto que tienen los hombres de lo femenino y, así, examinando los tratados de educación escritos por hombres sobre el tema,

7 \&I war not with an individual when I contend for the rights of men and the liberty of reason. You see I do not condescend to cull my words to avoid the invidious phrase, nor shall I be prevented from giving a manly definition of it...» (la cursiva es mía). Mary Wollstonecraft, $A$ Vindication of the Rights of Men, eds. Marilyn Butler and Janet Todd, Pickering \& Chatto Ltd. 1990, p. 7. En las referencias sucesivas a la obra se indican los números de las páginas en el texto entre paréntesis.

8 *Even the ladies, Sir, may repeat your sprightly sallies and retail in theatrical attitudes many of your sentimental exclamations». Ibid. p. 8. 
concluye que éstos «considering females rather as women than human creatures, have been more anxious to make them alluring mistresses than affectionate wives and rational mothers» (3). No deja de ser interesante la oposición entre women y human creatures lo que revela la génesis de la privación a la mujer de reconocimiento racional y, por consecuencia lógica, de su capacidad de erigirse en sujeto autónomo equiparable en derechos al sujeto universal «hombre». El convencimiento mediante una educación adecuada de que carece de esta facultad está en la base de la desposesión de su identidad como sujeto, ya que el único sujeto humano es el racional y, por tanto, el masculino, el único poseedor de la cualidad específica que lo distingue de los demás seres de la creación.

Reducida al estado de naturaleza, el de la sensualidad y la sexualidad reproductora, la mujer se convierte en una criatura cuyo instinto hay que orientar y encauzar, como se hace con la naturaleza para que no se convierta en destructiva. La educación llevará a cabo esa función encargándose de reprimir cuanto se oponga al fin femenino específico.

La trampa es perfecta porque la educación incita a la mujer a perfeccionar sus artes de seducción mediante el halago masculino y la promesa del poder sobre el corazón de quien detenta el poder mismo. Toda la educación de Sophie, el tratado educativo de la mujer por excelencia de la época, gira en torno a este principio. Ahora bien, la seducción es, como la naturaleza, peligrosa fuera de sus cauces, y la educación determinará cuáles son esos cauces y cuáles los medios de asegurarlos con firmeza. De este modo, una vez convenido que el papel de la mujer es complacer y seducir al hombre y reinar en su corazón, es el hombre el que determina la naturaleza y los límites de la complacencia, la seducción y el reinado. Para evitar las extralimitaciones fijará sutilmente los términos explícitos: la complacencia mediante la bondad, la sumisión, la dulzura, etc.; y los implícitos mediante la gratificación de los aspectos «menos nobles» de la persona: la sensualidad y el sexo. Los términos de la doble moral están ya garantizados. La educación será el difícil arte del equilibrio y se orientará a la represión femenina en aras de una pretendida virtud llamada a establecer las fronteras.

En realidad, la educación así concebida cumplía simultáneamente una función defensiva porque permitía al hombre dominar cuanto de turbulento e irracional percibía en el fondo de sí mismo mediante su proyección en otro ser lo suficientemente semejante como para posibilitar la proyección, y lo suficientemente diferente y débil -y en virtud de ello inferior- como para posibilitar el dominio.

Toda la Vindication of the Rights of Woman está fundamentada en el empeño de exponer la trampa del argumento. Wollstonecraft, una y otra vez, des- 
de uno y otro ángulo, da vueltas al mismo objetivo: recuperar la racionalidad para la mujer, lo único que puede devolverle su identidad como sujeto libre, igual al hombre que se la ha usurpado. Y ello haciéndole caer en la cuenta de la trampa que suponen el halago de la seducción de la belleza y la sensualidad que al debilitar y atrofiar su entendimiento la colocan en su posición de subordinación.

Mary Wollstonecraft se educó en la confesión evangélica y este espíritu, profundamente religioso, impregna toda la obra. La moralidad y el ejercicio de la virtud son preocupaciones constantes y argumentos que esgrime con frecuencia en defensa de la libertad de las mujeres para pensar, decidir y actuar racionalmente con independencia de los hombres. A ellos les achaca la responsabilidad sobre la inmoralidad y sensualidad de que acusan a las mujeres, aduciendo que la educación a que las someten es la causante del vicio que denuncian. Si a la mujer se la educa como uuna esclava de la sensualidad» cómo se va a requerir de ella que resista tal sensualidad en las ocasiones más peligrosas. Debiera en cambio esperarse más modestia de los hombres, puesto que ejercitan más su inteligencia (137). Su protestantismo le lleva asimismo a no admitir interferencia de otra mediación entre ella y Dios, «...becoming dependent only on Him for the support of my virtue, I view with indignation, the mistaken notions that enslave my sex», afirma; y continúa: «I love man as my fellow; but his sceptre, real or usurped, extends not to me unless the reason of an individual demands my homage; and even then the submission is to reason and not to man» (41).

Su preocupación por la primacía de la razón le lleva incluso a afirmar que una verdadera relación matrimonial debe basarse sobre la amistad, el lazo que considera más sagrado, contraponiéndolo a la pasión e incluso al amor, que considera sentimientos siempre efímeros. En un pasaje escribe que el amor sólo existe en esta tierra en la apasionada pluma del genio, en imaginaciones exaltadas que han bosquejado peligrosas fantasías (81), llegando a afirmar que en el matrimonio es preferible que no exista, porque de ese modo los padres se preocuparán mejor de sus hijos. La posibilidad de independencia económica que procuraría a las mujeres el ejercicio de una actividad remunerada las libraría de recurrir al matrimonio como a una forma de prostitución solapada, es decir como medio de procurarse el sostenimiento económico (162).

Una parte sustancial de la Vindication es la polémica con Rousseau. Wollstonecraft toma uno por uno los puntos que configuran la concepción de la mujer de Rousseau y los va demoliendo sistemáticamente.

Rousseau afirmaba que la mujer era débil y pasiva porque su fuerza corporal era menor que la del hombre y de ahí deducía que había sido creada para someterse a él, siéndole grata, lo que constituía el fin de su existencia. La mu- 
jer utilizaba su debilidad para conseguir la protección del hombre. Y ello, mediante la excitación de sus deseos, lo que le convertía en un ser dependiente de ella para satisfacerlos. Rousseau legitimaba esta interdependencia en una ley inmutable de la naturaleza que Wollstonecraft califica de alucinación de la razón (87).

De la demostración de Rousseau de que el hombre y la mujer no poseían igual temperamento y carácter, se seguía por la lógica del mismo argumento, que no debían ser educados del mismo modo. La educación de la mujer debía siempre ser relativa a los hombres, en función de la misma relatividad de su posición, y ello había de ser inculcado desde la infancia. El hombre debía desarrollar sus poderes corporales y la mujer sus encantos personales. Para Rousseau, la educación no consistía sino en estimular una propensión primaria y esta propensión la demostraba con la observación de la distinta índole de las aficiones de los niños y las niñas desde su infancia, éstas a las muñecas y los vestidos, aquéllos a los deportes y juegos activos y ruidosos. Wollstonecraft replicará que es la educación la que fomenta la tendencia de las niñas y achaca al ambiente francés, en el que Rousseau se movía, y al que califica de frívolo y licencioso - algo, por cierto, muy inglés - la obsesión sensual que fomenta la escuela de la coquetería y el artificio. Wollstonecraft se lamenta de que la naturaleza, a la que el filósofo francés tanto alude y exalta, actúe como madrastra en vez de madre en esta "segunda creación" de la mujer, al educar a las niñas por la fuerza en el decoro y la contención, caso de que estas cualidades no fueran en ellas todo lo naturales que se requiriese.

A la recomendación que el filósofo propone a la mujer de emplear la astucia y demás ardides del género —otorgados como compensación justa a su debilidad física, dado que no posee otras armas a su favor más que la astucia y la belleza- como medio de «regular» al hombre, Wollstonecraft responde con la ética: "Greatness of mind can never dwell with cunning» (94). Expone además la inconsistencia de la paradoja rousseauniana de que, según el orden de la naturaleza, el marido sea el maestro y reclame obediencia, pero según el mismo orden de la naturaleza, ella deba dirigirlo manteniendo su autoridad sobre su corazón y empleando para ello las artes de la coquetería. Wollstonecraft contrapone este texto con otro del filósofo, de nuevo contradictorio, en el que reconoce la naturaleza temporal del amor y su necesaria sustitución en el matrimonio por una relación de amistad ya que en la institución matrimonial la mujer es ante todo madre. Se pregunta entonces si el método recomendado en el caso anterior es el más indicado para alcanzar el objetivo del segundo estadio del matrimonio, como compañera y madre juiciosa.

La crítica a Rousseau concluye con una vibrante declaración de rebelión contra todo poder basado en prejuicios y con una no menos vibrante apelación 
a la confianza en las propias fuerzas. «They are free - who will be free!» (111), exclama, aunque el ardor no le oculta que esta libertad tiene un precio que ha de pagarse, afirma, "to the last farthing».

Mary Wollstonecraft pagó realmente muy caro su independencia de espíritu y la osadía de coger la pluma y escribir un tratado ideológico - actividad reputada como masculina - para defender a las mujeres. Muchas de ellas, por otra parte, cegadas por el brillo fatuo del halago y la apelación a una noción de la feminidad ornamental e idealizada, consideraban que no necesitaban ser defendidas, como la propia autora de la Vindication había observado: «...Becoming the slave of her own feelings she is easily subjugated by those of others. Thus degraded her reason, her misty reason! is employed rather to burnish than to snap her chains» (111).

De nuevo es interesante observar la voz narrativa y constatar que su vibrante defensa de la mujer se lleva a cabo, como en la obra anterior, desde el discurso masculino imperante. A Vindication of the Rights of Woman se abre con una afirmación de principios que establece la polaridad retórica entre el discurso del racionalismo filosófico y el de la ornamentación literaria. Wollstonecraft se pronuncia explícitamente por el primero, desdeñando el segundo. «I wish to speak the simple language of truth, and rather to address the head than the heart» (31). Al asociar aquél con la cabeza y a este último con el corazón, a aquél con la verdad, y a éste, por implicación con lo que no lo es, no hace sino reforzar la estructura de oposiciones binarias que subyace al pensamiento de la Ilustración y que conceptualiza a la mujer como el polo negativo del hombre, como aquello que el hombre no es. Su objetivo es la liberación de la mujer de las falsas concepciones acuñadas de su género. Tanto de las identificables fácilmente en el prejuicio masculino, las menos peligrosas precisamente por ser detectables, como de aquellas que al haber sido interiorizadas por la propia mujer, ni siquiera ella es consciente de que están construyendo su identidad en el sentido de la fantasía masculina, como la argumentación con Rousseau pone de relieve.

El problema es que el paradigma, como ocurría en la anterior Vindication, la de los derechos de los hombres, en la que «hombres» era literalmente el paradigma de sujeto universal, sigue siendo el sujeto masculino al que la mujer tiene que aproximarse. Wollstonecraft no solamente aboga por el discurso masculino de la razón, expresado en una retórica masculina, enérgica y dinámica sin concesiones a la ornamentación estilística, sino por una educación masculina de la mujer y una consideración masculina del problema.

En este sentido, aunque insiste en el carácter cultural y construido de la mal llamada naturaleza femenina y lo explora desde el concepto de grupo so- 
cial, analizando diferentes grupos de mujeres: las románticas, las ignorantes, las ociosas, la voz narrativa se identifica con los críticos masculinos ${ }^{9}$, se dirige a los hombres, a los que interpela para que liberen y así dignifiquen a la mujer ${ }^{10}$ y erige, en definitiva, al hombre y a las virtudes masculinas como modelo de lo humano ${ }^{11}$.

Esta posición autorial resulta hoy y resultó en su momento ambigua y problemática. En el Prefacio de la Vindication afirma:

«I wish to persuade women to endeavour to acquire strength, both of mind and body and to convince them that the soft phrases, susceptibility of heart, delicacy of sentiment, and refinement of taste, are almost synonimous of weakness» (5).

Al criticar esta «noción equivocada de la excelencia de la mujer» como textualmente escribe, está atacando toda la ideología sobre la feminidad que se había ido desarrollando a lo largo del siglo y que ella misma había absorbido y cultivado, como demuestra su primera novela, Mary: A Fiction. En la vindicación se retracta claramente, dejando bien explícito que la inferioridad intelectual de la mujer se debe sin duda alguna a la opresión masculina, pero también a una noción de sensibilidad femenina radicalmente errónea y responsable en buena medida de esa misma opresión. Sexualidad y pasión, los ocultos sinónimos de la sensibilidad ${ }^{12}$ son la trampa que la naturaleza tiende a las mujeres y el único modo de librarse es a través de la razón.

Pero Wollstonecraft al reclamar para sí el discurso de la razón que los hombres, por muy admiradores que fueran de la escritura femenina, sobre to-

9 «After surveying the history of woman I cannot help agreeing with the severest satirist, considering the sex the weakest as well as the most oppressed half of the species. What does history disclose but marks of inferiority...? p. 39.

10 Es muy frecuente este tipo de interpelación a los hombres en favor de las mujeres: «Cultivate their minds..., teach them... (41), make them free... (194), make women rational creatures and free citizens...» (197).

11 «From every quarter have I heard exclamations against masculine women, but where are they to be found? If by this appellation men mean to inveigh against their ardour in hunting, shooting and gaming, I shall most cordially join in the cry, but if it be against the imitation of manly virtues, or more properly speaking, the attainment of those talents and virtues, the excercise of which ennobles the human character, and which raises female in the scale of animal being, when they are comprehensively termed mankind, all those who view them with a philosophic eye must, I should think, wish with me, that they may every day grow more and more masculinew. (4) (La cursiva es mía).

12 Vid. Janet ToDD, The Sign of Angellica, London: Virago, 1989, p. 241. 
do de algunas féminas escritoras, se habían reservado, estaba infringiendo peligrosamente los términos de un acuerdo tácito. Su atrevimiento y la claridad de sus objetivos barrieron literalmente la caballerosidad masculina y pusieron de relieve, sin tapujos, la naturaleza del prejuicio. La reseña que recibió la Vindication of the Rights of Woman en la Critical Review decía así:

«Women we have often eagerly placed near the throne of literature, but if they seize it, forgetful of our fondness we can hurl them from it» ${ }^{13}$.

Por otra parte, la vindicación, con todo lo vibrante de su defensa de una naturaleza racional para la mujer, con el consiguiente reconocimiento de su identidad de sujeto, no establece la consecución del objetivo que nunca rebasa el estadio de proyecto. Como afirma Jane Moore en un sugerente análisis deconstructivo de la obra ${ }^{14}$, el desenlace se difiere incesantemente sin jamás concluir. Lo que late vibrante es el aliento perenne del deseo, de la exhortación, pero a pesar de la urgencia de la apelación a la recuperación del reconocimiento de sujeto, su consecución se remite a un futuro harto improbable, lleno de condiciones, cuando la mujer cobre conciencia de su capacidad racional, cuando se libere de la trampa de la sensualidad y el halago, cuando el hombre la eduque en la libertad, cuando...

Entre las dos vindicaciones y la última obra, la novela The Wrongs of $W_{o m a n}{ }^{15}$, se produce un cambio significativo. Comentaba al principio la modificación que la praxis va ejerciendo sobre la teoría a lo largo de la vida y la obra de Mary Wollstonecraft. Aquellas se escribieron en la atmósfera y el círculo de los radicales disidentes entre los que Mary se movía y trabajaba. En pleno fervor revolucionario, en el clima de expectación de libertad y progreso prometidos por la razón que alentaba en los ambientes ilustrados. Esta última, inacabada, y publicada sólo póstumamente, se escribe tras el periodo del Terror, vivido personalmente en Francia, con el regusto amargo de una pasión consumada y exhausta, la experiencia del desamor y el abandono, la soledad, una hija ilegitma y dos intentos de suicidio.

13 Cit. en Jane SPEnCER, The Rise of the Woman Novelist. From Aphra Behn to Jane Austen, Oxford: Basil Blackwell, 1986, p. 100.

14 Jane MOORE, «Promises, Promises: the Fictional Philosophy in Mary Wollstonecraft's Vindication of the Rights of Woman en The Feminist Reader. Essays in Gender and the Politics of Literary Criticism, eds. Catherine Belsey and Jane Moore, London: Macmillan, 1989, pp. 156-173.

15 Mary Wollstonecraft, Mary and The Wrongs of Woman, Oxford: Oxford University Press, 1991 (1976). En todas las referencias a la obra las páginas van en el texto entre paréntesis. 
El cambio que se advierte hacia una revaloración del sentimiento como norma de conducta, se inscribe, pues, tanto en la propia experiencia vital de la autora como en el escepticismo ante la evidencia de que ni el celo revolucionario ni el énfasis en la razón parecían conducir a reformas inmediatas en cuanto a la consideración de la mujer se refería ${ }^{16}$.

En este sentido, The Wrongs of Woman puede leerse como una reconceptualización literaria de los argumentos filosóficos de la obra precedente The Rights of Woman. Ambas comparten idéntico proyecto: el mostrar "the misery and oppression peculiar to women, that arise out of the partial laws and customs of society" como en la novela se afirma (73). Pero la focalización es radicalmente distinta. Se ha producido el reverso de las oposiciones binarias filosofía/literatura, lenguaje abstracto/ornamental, verdad/ficción, masculino/femenino. La mujer pasa de constituir el objeto de análisis, cuya situación se disecciona desde fuera, a erigirse ella misma en sujeto y explorar su situación desde el núcleo de su experiencia femenina. En lugar de apropiarse de los elementos masculinos y de identificarse con el discurso falocrático de la razón, elegirá los que socialmente han construido la noción de sensibilidad femenina para mostrar desde ellos su caracter opresivo y explotador.

La identificación entre la autora y la voz narrativa es evidente en este texto. Elementos autobiográficos, identificación nominal de heroína y autora, y el relato confesional en primera persona que constituye el núcleo de la obra, confluyen en una perspectiva claramente diferenciada de la posición autorial y conceptual de las dos Vindications. La voz narrativa en The Wrongs of Woman manifiesta una opción que incluye la experiencia femenina desde la solidaridad con el género, muy lejos de la distancia que exhibía en las Vindications. El tono también ha cambiado. En esta obra es comprensivo y surge de una empatía situacional muy lejos de la irritada exasperación que destilaba en las anteriores.

Paralelamente se desvanece el modelo masculino y la peripecia articulará en toda su crudeza la indefensión absoluta de la mujer en una sociedad cuya configuración misma, junto con las leyes que sostienen su existencia, le es profundamente hostil. Combina, de este modo, el análisis de la experiencia in-

16 Vid. el estudio sobre el fraude de las expectativas de reconocimiento de los derechos de la mujer llevado a cabo por la revolución francesa y el trágico destino de mujeres como Olympe de Gouges o Madame Roland, en las Actas del Seminario permanente Feminismo e llustración 1988-1992, Madrid: Instituto de Investigaciones Feministas, Universidad Complutense, 1992, particularmente los artículos «Revolución Francesa y crisis de legitimación patriarcal» de Celia Amoros, pp. 155-162, y «La radical universalización de los Derechos del hombre y del ciudadano: Olympe de Gouges» de Alicia Puleo, pp. 215-220. 
dividual con una nueva dimensión de solidaridad e identidad de grupo, a través del reconocimiento de una experiencia de subordinación compartida. Con ello el examen de la subjetividad adquiere una dimensión y un significado de representatividad transubjetiva.

La novela presenta a dos mujeres, Maria y Jemima, igualmente victimizadas, aunque por razones distintas debido a sus circunstancias, particularmente a su entorno social. La diferencia social subraya la universalidad de la condición femenina que, a diferencia de los hombres, trasciende los límites de clase. Maria está recluida a la fuerza en un psiquiátrico por un marido que pretende incapacitarla legalmente y desposeerla, así, de su fortuna. Jemima, la celadora, ha llegado al mismo lugar por la vía harto conocida de la perdición femenina: abandono en la infancia-pobreza-violación-mayor abandono-mayor pobreza-prostitución. Si en The Rights of Woman, Wollstoncraft había denunciado la prostitución «legalizada» en el matrimonio, en The Wrongs of Woman muestra lo plausible del hecho y la reducción de la mujer a puro objeto de transacción económica, en la relación que describe entre Maria y su esposo quien no vacila, cuando llega el caso, en ofrecerla a un amigo a cambio de un préstamo.

Matrimonio y seducción aparecían tradicionalmente en la novela de la época como los polos de referencia del paradigma de retribución a la virtud femenina. El matrimonio, como premio a la heroína que sorteaba con inteligencia los obstáculos y avatares del crecimiento, coronaba su integración social y constituía el centro de gravedad en torno al cual giraba la peripecia. En sus márgenes, el otro polo apenas si se insinuaba más que como contrapunto amenazador, disuasorio frente a la transgresión de la norma. Situación sin retorno, la distancia entre la mujer de ambos campos era insalvable. Wollstonecraft va a subvertirlos, construyendo una insólita historia de solidaridad entre mujeres en la que Jemima facilita la huida de Maria.

La novela subvierte, además, la historia clásica de la seducción, considerada como perdición y deshonra y, como tal, tratada. Con ello dota de carnadura a un tema también tratado en la Vindication. Si a la mujer se la educa en el exclusivo arte de agradar al hombre y seducirlo, ¿qué ocurriría cuando por cualquier evento - la erosión del tiempo, la sensualidad del marido- perdiera el favor de éste? En la reclusión del psiquiátrico, Maria, separada de su hija recién nacida, aislada, con Rousseau por toda compañía, proyecta ilusoriamente las virtudes de St. Preux, el protagonista masculino de La Nouvelle Heloise, en un desconocido recluso, el único ser normal encerrado en la celda contigua y con quien inicia una relación subrepticia. La ironía no puede ser más patente. La prisión de Maria es simbólica de la mujer en un mundo al que define como una «vasta prisión» en la que es «esclava por nacimiento». Maria 
es metáfora de la mujer confinada, sin actividad que ensanche su mente, tan denunciada en la Vindication of the Rights of Woman, sin posibilidad de acción libre, a merced no sólo de caer víctima del engaño de un otro sino del de los propios sentimientos ${ }^{17}$. Si Wollstonecraft muestra a su heroína la primera vez engañada premeditadamente por un hombre que abusa de sus sentimientos más nobles, la segunda vez es víctima de una ilusión romántica producto de su reclusión y de sus lecturas sentimentales, peligro este último asimismo advertido en la Vindication.

Además de atreverse a elegir como argumento el tema tabú de la seducción y el adulterio, la novela reivindica el reconocimiento y el derecho de la mujer a su sexualidad. Habíamos visto en la Vindication la desconfianza global de su autora hacia cualquier tipo de sentimiento, incluido el sexual, lo que justificaba afirmaciones tales como que un matrimonio desgraciado era más ventajoso para la familia porque una madre abandonada era, en general, mejor madre, naturalmente siempre y cuando se la hubiera educado de una manera más racional y menos sentimental. Por boca de Maria, Wollstonecraft va a expresar ahora sin el menor reparo la repulsión que experimenta cuando novelistas y moralistas ensalzan a la mujer por la ausencia de pasión que supuestamente caracteriza su constitución femenina, afirmando la imposibilidad, a menos de caer en la depravación, de siquiera intentar complacer a un marido o a un amante «but in proportion as he pleases us» (153).

El permitirse mostrar sin ambages en una novela que los sentimientos influyen explícitamente en la actuación de la mujer en la vida es, así, a la vez rebelión contra el estrecho concepto social de la feminidad y exposición y denuncia de la incongruencia de tal reduccción de lo femenino. Pero aún se desvela una reducción adicional y es la constricción dentro de los sentimientos a los que se ha encogido el arquetipo femenino, a los conducentes a la abnegación y al sacrificio. En el juicio que sigue a la huída de los amantes, el juez condena a Maria por esta razón, aludiendo a la falacia de permitir que las mujeres utilizaran sus sentimientos como justificación de sus actuaciones con el argumento de que ello abriria las compuertas de la inmoralidad, porque "What virtuous woman thought of her feelings?» (199).

La novela resultó explosiva al dinamitar por su base el núcleo mismo de la esencia femenina. Ciertamente The Wrongs of Woman era un auténtico alegato contra una noción opresiva e hipócrita de sensibilidad femenina y a favor del derecho de la mujer a su libertad amorosa y sexual, fruto de la auténtica sensibilidad. El problema radicaba en la extensión del juicio moral del sentimiento

17 Vid. Jane SPENCER, op. cit. p. 135. 
al acto. Si aquél era auténtico éste debería ser conceptuado como bueno. Por tanto una relación amorosa basada en un sentimiento genuino era moralmente legítima, en tanto que situaciones socialmente sancionadas como tal, eran de hecho moralmente indignas. La protagonista de The Wrongs of Woman en ningún momento se culpabiliza sobre lo que en la novela sentimental constituía el delito moral sin redención posible. Al contrario, como sugiere Felsky ${ }^{18}$, con la exploración y la afirmación de su subjetividad, explícitas en el género confesional, apela a una autoridad más alta que la de la convención social.

Su publicación levantó un indescriptible escándalo, no, como pudiera parecer, por situaciones escabrnsas, ya que era en ese sentido irreprochable, sino por su contenido ideológico que trastocaba de modo imposible el núcleo mismo de la estructura patriarcal.

Publicada tras la muerte de Mary, irritantemente la más femenina de todas las muertes, de septicemia postpueral, por Godwin, el filósofo radical con quien hacía tan sólo unos meses que había contraído matrimonio, levantó una formidable polémica. En el clima de pánico nacional ante el rumbo que tomaban los acontecimientos en Francia, a Godwin no se le ocurrió nada mejor que publicarla con un libro, Memorias, en el que hacía un retrato del carácter de su mujer y relataba su vida. Comentaba en él ampliamente sus amores, sus intentos de suicidio al verse abandonada por su amante, el americano Imlay, con una hija, y la abdicación de sus creencias religiosas. La reacción del público, no es necesario explicar, fue de horror y fascinanción morbosa. Se desató una campaña de prensa de insultos a su persona y de denigración de sus ideas, achacando a estas últimas las causas de su «escandalosa» conducta. Sus obras fueron proscritas como peligrosas y se produjo una reafirmación social respecto al carácter nocivo de las ideas «avanzadas» $y$, en consecuencia un retroceso en el arduo camino de la emancipación femenina. No faltó siquiera la apostilla de un reverendo clérigo remachando las diferencias imposibles que determinaban la distinción entre los sexos al establecer el destino de las mujeres ligado a su peculiar naturaleza, de lo que la muerte de Mary Wollstoncraft era pertinente ejemplo.

Hay que decir que la responsabilidad de Godwin en todo ello no fue poca. El propio retrato que ofrecía de su mujer no hizo el menor servicio a la causa que Mary había defendido con tanto apasionamiento y energía. En una segunda edición, con algunas modificaciones y aclaraciones para apaciguar los ánimos, minimizaba su perfil intelectual y su aportación ideológica, resaltando a

18 Rita Felsky, Beyond Feminist Aesthetics. Feminist Literature and Social Change, Cambridge, Mass.: Harvard University Press, 1989, p. 104. 
cambio sus dotes de intuición, y - un detalle interesante- describiendo con qué perfección este tipo de conocimiento intuitivo, femenino, completaba el suyo propio, abstracto y filosófico. La cita, no tiene desperdicio:

«The strength of her mind lay in intuition. She was often right, by this means only, in matters of mere speculation... and yet, though perhaps, in the strict sense of the term, she reasoned little, it is surprising what a degree of soundness is to be found in her determination. But if this quality was of use to her in topics that seem the proper province of reasoning, it was much more so in matters directly appealing to the intellectual taste. In a robust and unwavering judgement of this sort, there is a kind of witchcraft ${ }^{19}$.

El círculo se cerraba de nuevo. Lo de menos eran los argumentos que se esgrimían, tan pronto los de la razón como los de la irracionalidad. Con la algarabía y el escándalo lo que se proponía, y se consiguió por un tiempo, era sofocar la amenaza de la emergencia de un sujeto femenino con la osadía de afirmarse como tal, con pretensiones de independencia de criterio, de capacidad de agencia y de igualdad ante la ley. Asombra, una vez más, la persistencia con la que el hombre prefiere abandonar la senda de la racionalidad en cuanto se siente amenazado, consignando al mundo oscuro de la naturaleza, a la brujería, cuanto hace tambalear su lógica.

La obra de Wollstonecraft anticipa, así, y evidencia en toda su crudeza, la problematicidad ontológica de la mujer como sujeto, sea cual sea el modelo de identidad que se proponga, el de la igualdad o el de la diferencia. Y demuestra que, sea cual sea la opción, en virtud de la conceptualización que se lleve a cabo de su naturaleza, la cuestión es finalmente política. La autora lo entendió perfectamente. Si su Vindication of the Rights of Woman es un discurso político, su novela The Wrongs of Woman no lo es menos. En primer lugar, a través de la escritura se confiere realidad a una experiencia de mujer silenciada y suprimida y, por tanto, socialmente invisible. En segundo término, a la vez que acentúa la dimensión personal y subjetiva de la experiencia, está resaltando y poniendo en evidencia la naturaleza institucionalizada de la opresión sexual. En definitiva, a través de dos modos diferentes de argumentación trata de persuadir a hombres y mujeres de la legitimidad de la crítica de la sociedad patriarcal.

19 Cit. en Claire Tomalin, The Life and Death of Mary Wollstonecraft, Harmondsworth: Penguin, 1985 (1974), p. 294. La cursiva es mía. 